\title{
BMJ Open Death of a parent during childhood and blood pressure in youth: a population- based cohort study of Swedish men
}

\author{
Hua Chen (D) ," Tomas Hemmingsson, ${ }^{2,3}$ Imre Janszky, ${ }^{1,4}$ Mikael Rostila, ${ }^{2,5}$ \\ Yvonne Forsell, ${ }^{1,6}$ Linghui Meng, ${ }^{1,7}$ Yajun Liang, ${ }^{1}$ Krisztina D. László (DD ${ }^{1}$
}

To cite: Chen $\mathrm{H}$, Hemmingsson T, Janszky I, et al. Death of a parent during childhood and blood pressure in youth: a population-based cohort study of Swedish men. BMJ Open 2021;11:e043657. doi:10.1136/ bmjopen-2020-043657

- Prepublication history and additional supplemental material for this paper are available online. To view these files, please visit the journal online (http://dx.doi.org/10.1136/ bmjopen-2020-043657).

Received 10 August 2020 Revised 22 February 2021 Accepted 12 April 2021
Check for updates

(c) Author(s) (or their employer(s)) 2021. Re-use permitted under CC BY. Published by BMJ.

For numbered affiliations see end of article.

Correspondence to Dr Hua Chen; hua.chen@ki.se

\section{ABSTRACT}

Objective Compelling evidence suggests that childhood adversities are associated with an increased risk of hypertension in middle age and old age. The link between childhood adversities and blood pressure in youth is less clear. In this cohort study, we examined the association between death of a parent during childhood and blood pressure in early adulthood in men.

Setting Sweden.

Participants We studied 48624 men born in 1949-1951 who participated in the compulsory military conscription in 1969/1970 in Sweden. Information on death of a parent during childhood was obtained from population-based registers. Information on covariates was obtained from the questionnaire and the clinical examination completed at conscription and from population-based registers. Outcome measures Blood pressure was measured at conscription according to standard procedures.

Results The multivariable least square means of systolic and diastolic blood pressure did not differ between bereaved (128.25 (127.04-129.46) and 73.86 (72.89$74.84) \mathrm{mm} \mathrm{Hg}$ ) and non-bereaved study participants (128.02 (126.86-129.18) and 73.99 (73.06-74.93) mm $\mathrm{Hg}$ ). Results were similar when considering the cause of the parent's death, the gender of the deceased parent or the child's age at loss. Loss of a parent in childhood tended to be associated with an increased hypertension risk (OR and 95\% Cl: 1.10 (1 to 1.20)); the association was present only in case of natural deaths.

Conclusion We found no strong support for the hypothesis that stress following the loss of a parent during childhood is associated with blood pressure or hypertension in youth in men.

\section{INTRODUCTION}

Death of a parent is one of the most traumatic and stressful events that a child can experience. ${ }^{1}$ In the Nordic countries around $4 \%$ of children experience parental death before the age of 18 years, ${ }^{23}$ while in the developing countries the prevalence is higher. ${ }^{4}$ Children exposed to parental death have an increased risk of experiencing poor social support, ${ }^{6}$ heightened stress reactivity, ${ }^{7}$ poor school performance, ${ }^{8}$ emotional and behavioural problems, ${ }^{6}$ psychiatric

\section{Strengths and limitations of this study}

- This is the first study to investigate prospectively the association between parental death in childhood and blood pressure measured in early adulthood in a large national cohort; the prospective design limited recall bias, while the large national sample allowed to reduce selection bias and to conduct subanalyses to test hypotheses that may be supportive of a causal effect, if any.

- Since only one or two blood pressure measurements were taken, there was no possibility to consider intra-individual variations in blood pressure or to reduce the impact of white-coat hypertension.

- Information on some potential confounders was not available.

- It is not clear to what extent our findings are generalisable to women, to current Swedish young adults or to populations with different risk factor profiles, support for bereaved children and healthcare.

disorders, ${ }^{9}{ }^{10}$ substance use, ${ }^{11}{ }^{12}$ obesity $^{13}$ and/or metabolic syndrome. ${ }^{14}$ These in turn may induce stress-related physiological changes related to the dysregulation of the hypothalamic-pituitary-adrenocortical axis and of the sympathetic nervous system; these enhance pro-inflammatory activity and may overactivate the renin-angiotensin-aldosterone system. ${ }^{15}$ Chronic stress may also lead to unhealthy lifestyle. ${ }^{16}$ Such physiological and behavioural changes may increase blood pressure (BP) and the risk of other cardiovascular diseases (CVD) (eg, ischaemic heart diseases, stroke) or cardiac mortality, ${ }^{17}$ already in young age. ${ }^{2}$

To our knowledge, only five studies investigated the association between death of a parent and BP and the findings have been inconsistent. ${ }^{4}$ 19-21 Luecken $^{7}$ and Anderson et $a t^{20}$ reported that study participants who experienced parental death during childhood had higher systolic BP (SBP) and diastolic BP (DBP) than their unexposed counterparts. In contrast, Schooling et at 
and Stein $e t a l^{21}$ found no association between parental death and BP or hypertension. In a study conducted later, Luecken et al found that university students who lost their parent had lower 24-hour ambulatory BP compared with non-bereaved students. ${ }^{19}$ Except for the studies conducted by Luecken $e t$ al, which assessed BP in childhood or in young adulthood, ${ }^{719}$ all other studies were conducted in middle-aged individuals and assessed exposure retrospectively ${ }^{4021}$; thus they could not eliminate selection bias, that is, that patients with severe hypertension may die before middle-age. A further potential explanation for the discrepant findings in these earlier studies may be related to differences in their multivariate adjustments; some investigators did not adjust at all for confounders, ${ }^{719}$ some adjusted for a limited number of confounders, ${ }^{41}$ while others adjusted for several factors that may be on the causal pathway between parental death and hypertension. ${ }^{20}$

None of these earlier studies investigated the importance of the type of the parent's death, analyses often conducted in bereavement research to attempt to separate the effect of stress from confounding or to investigate dose-response effects. The effect of exposure to parental death due to natural causes, in particular those due to CVD, on the risk of hypertension is likely to be confounded by genetic and environmental cardiovascular factors shared by family members, for example, socioeconomic factors, lifestyle, mental health, cardiometabolic risk factors and morbidity; in contrast, the importance of familial confounding by cardiovascular risk factors is likely to be substantially more modest for unnatural deaths. $^{22}$ Furthermore, unnatural deaths have been suggested to be more strongly associated with stress and an increased risk of complicated grief than deaths due to natural causes. ${ }^{61623}$ Similarly, maternal death may have a more negative effect on BP than paternal death since in most cultural contexts mothers have stronger emotional bonds with their children, are more involved in their children's upbringing, ${ }^{24}$ have a stronger impact on their children's health behaviour and are likely to provide more emotional support for coping with grief than fathers. ${ }^{25}$ Similarly, the first few years of life and adolescence could be particularly sensitive periods with respect to stress. Losing a parent in the first few years of life may be particularly detrimental ${ }^{26}$ as warm relationships with caregivers are critical for the development of the brain architecture and the programming of stress reactivity, ${ }^{7}$ while loss of a parent in adolescence, another period with an increased stress sensitivity, may result in taking up adverse health behaviours that increase the CVD risk. ${ }^{27}$

High BP in youth tracks into adulthood and is an important predictor of later hypertension and $\mathrm{CVD}^{28}{ }^{29}$; it is associated with increased risks of abnormal left ventricular mass, ${ }^{30}$ metabolic syndrome, ${ }^{31}$ impaired cognitive ability, ${ }^{32}$ renal damage ${ }^{33}$ and cardiovascular and total mortality. ${ }^{34} 35$ The prevalence of elevated BP among children and young adults has been increasing. ${ }^{36}{ }^{37}$ Though adverse childhood experiences (most often defined in terms of maltreatment and family dysfunction), are associated with an increased risk of hypertension in middle age and old age ${ }^{1538} 39$ knowledge about their association with high $\mathrm{BP}$ in youth is more limited. ${ }^{40-43}$

We investigated the association between parental death during childhood-one of the most severe childhood adversities-and BP at the age of 18-20 years in a cohort of Swedish men. We also analysed whether this association differs by the parent's gender, cause of death and the child's age at loss.

\section{METHODS}

\section{Study population and design}

This study was based on a cohort consisting of 49321 men born in 1949-1951 and who were conscripted for military service in Sweden in 1969-1970. The cohort includes $97 \%-98 \%$ of all Swedish men of conscription age $(\approx 18-20$ years); the $2 \%-3 \%$ that were exempted from participation had severe congenital disorders or intellectual disabilities. ${ }^{44}$ At conscription, participants completed an extensive questionnaire and participated in a clinical examination performed by a team of physicians, psychiatrists and psychologists. The conscription data were linked to several nationwide registers through the unique personal number. We excluded participants with no information on exposure $(n=314)$, missing $\mathrm{BP}(\mathrm{n}=369)$ or higher DBP than SBP $(n=14)$, resulting in 48624 men being included in our analysis.

\section{Measures}

\section{Exposure}

Conscripts were linked to their parents using the Multigeneration Register. We obtained information on the date and the cause of the parent's death after 1952 from the Cause of Death Register; causes of death were recorded according to the International Classification of Diseases (ICD). We classified the cause of the parent's death as due to unnatural causes (ICD-6: 795 and 800-999; ICD-7: 795 and 800-999; ICD-8: 79599, 796 and 807-999), due to nonrheumatic CVD (ICD-6: 400-468; ICD-7: 400-468; ICD-8: 400-458) and due to other natural causes (the rest of the ICD codes). For the conscripts whose parents did not appear in the Cause of Death Register, we used two items from the questionnaire completed at conscription to determine their exposure status before 1952: 'Are both of your parents alive' (yes/no), and 'Whom have you mostly lived with' (with both parents/mother/father/somebody else). If study participants responded 'no' to the first question, the gender of the deceased parent was determined using the second question: (1) having lived with the mother was coded as paternal death, (2) having lived with the father was coded as maternal death and (3) having lived with both parents or somebody else was coded as having no information on the deceased parent's gender.

\section{Outcome}

BP was measured at conscription according to a written protocol; the measurement was performed in a supine 
position, after a 5-10 min rest, with an appropriately sized cuff at the heart level. ${ }^{4-46}$ Thus the measurement of BP in this study reflects the standard practice in primary care settings. ${ }^{46}$ The measured SBP and the DBP values were rounded to the nearest even number, or to the nearest 5 or $10 \mathrm{~mm} \mathrm{Hg}$. If the SBP was higher than $145 \mathrm{~mm} \mathrm{Hg}$ or if the DBP was lower than $50 \mathrm{~mm} \mathrm{Hg}$ or higher than $85 \mathrm{~mm}$ $\mathrm{Hg}$, another measurement was conducted the next day and the result of the second measurement was recorded; otherwise only one BP measurement was taken. Given that there is a linear association between $\mathrm{BP}$ in young age and the later risk of CVD ${ }^{47}$ that even BP values below 140/90 $\mathrm{mm} \mathrm{Hg}$ have a predictive value for the development of later CVD, and since both SBP and DBP are associated with later CVD risk, ${ }^{48} 49$ we considered the continuous SBP and DBP measures as the main outcome. In sensitivity analyses we also considered hypertension, defined as $\mathrm{SBP} \geq 140 \mathrm{~mm} \mathrm{Hg}$ and/or DBP $\geq 90 \mathrm{~mm} \mathrm{Hg}$.

\section{Covariates}

The occupation of the head of the household (generally the father) from the National Population and Housing Censuses of 1960 was used as a measure of parental socioeconomic status (SES). Occupation was classified as: non-manual at middle or high level, non-manual employee at low level, skilled worker, unskilled worker, farmer and other. ${ }^{51}$ Men who during the psychological interview reported or were suspected to have a psychiatric disorder were referred to a psychiatrist for further evaluation. We retrieved information on depression using ICD- 8 codes 296 and 300.4 and on anxiety using code 300.0 , respectively. We calculated body mass index based on height and weight assessed at the clinical examination. Cardiorespiratory fitness was assessed using a cycle ergometer submaximal exercise test performed after a normal resting ECG. The work rate was increased until the participants were volitionally exhausted; the resulting maximal work capacity divided by weight was transformed to stanine scores (1-9). ${ }^{45}$ The number of personal friends $(0,1-3,3-5$ or $>5)$, the frequency of confidentially discussions with friends (never, sometimes or quite often), having a confidant to talk about personal problems (no one, or parent/siblings/teachers or supervisor or manager/friends/others), number of cigarettes per day (>10,1-10 or 0$)$, risky drinking behaviour (defined as reporting any of the following: drinking $>250 \mathrm{~g} /$ week, having taken alcohol as an 'eye-opener' during a hangover, having been arrested for drunkenness or having often been intoxicated $)^{52}$ and father's drinking habit (often, or sometimes/occasionally/never) were assessed by questionnaires. We calculated a cumulative index of childhood adversities by summing the number of the adverse childhood experiences reported by questionnaire from the following: financial situation of the family (bad/very bad vs very good/good/average), paternal alcohol use (often vs never/occasionally/sometimes), parents' divorce (yes vs no), severe illness of parent (father/mother/both parents vs none), family member taking medicines for mental disorders (mother/father/ both parents/others vs no one), experiencing physical punishment (often/sometimes/once in a while vs never), strict upbringing (very strict/quite strict vs medium/ quite mild/very mild) and having multiple residences during childhood (more than three residences vs one/ two/three residences). We considered participants whose answer was in the first group to have been exposed to the corresponding adverse experience. We chose these adverse childhood experiences based on previous literature-which often defined adverse childhood experiences in terms of abuse (emotional, physical and sexual), neglect or family dysfunction ${ }^{15} 5354$-and the questionnaire completed at conscription. We calculated the cumulative index by summing the number of adverse events experienced, a common praxis in the literature ${ }^{155355}$ and based on evidence of a dose-response association between the number of adverse childhood experiences and the risk of CVD. ${ }^{5355}$

\section{Statistical analyses}

We compared characteristics of exposed and unexposed men by $\chi^{2}$ tests in case of categorical variables and Wilcoxon tests in case of continuous variables with a skewed distribution. We used similar tests and logistic regression to study the link between covariates and our outcomes. We performed general linear regression to investigate the association between parental death and the continuous SBP and DBP measures. For each exposure category, we also estimated least square means of SBP and DBP and their 95\% CIs. We performed analyses with any parental death during childhood and with exposure classified based on the cause of the parent's death, the gender of the deceased parent and the age of the child when the parent died. We ran three models. Model 1 was unadjusted. Model 2 was adjusted for childhood parental SES, a factor that is likely to be confounder of the investigated association. Model 3 was further adjusted for depression, anxiety, body mass index, cardiorespiratory fitness, number of friends, frequency of talking with friends confidentially, having a confidant, number of cigarettes smoked per day and risky drinking behaviour. We chose to run model 3 separately since we could not determine whether the variables in model 3 are confounders or mediators of the association under study; though their assessment after the exposure period may favour regarding them as mediators, several of these characteristics could have been present before the loss of a parent and may thus be confounders. To study whether father's drinking behaviour confounded the association between death of a father and BP, we re-ran these analyses after adjusting for father's drinking behaviour in addition to factors in model 3. To assure that the method of exposure assessment did not influence our results, we ran analyses after excluding the conscripts whose parent's death was identified only by questionnaire. We investigated effect modification by parental SES (classified as (1) nonmanual employee versus (2) unskilled workers or skilled 
Table 1 Characteristics of study participants according to death of a parent ( $\mathrm{N}=48$ 624)

\begin{tabular}{|c|c|c|c|c|}
\hline \multirow[b]{2}{*}{ Variables } & \multirow[b]{2}{*}{ Total, n (\%) } & \multicolumn{2}{|c|}{ Death of a parent } & \multirow[b]{2}{*}{ P value* } \\
\hline & & $\begin{array}{l}\text { Yes } \\
(n=3504)\end{array}$ & $\begin{array}{l}\text { No } \\
(n=45120)\end{array}$ & \\
\hline \multicolumn{5}{|l|}{ Categorical variables, $\mathrm{n}(\%)$} \\
\hline Parental socioeconomic status & & & & $<0.01$ \\
\hline Middle or high level non-manual employee & $10716(22)$ & $689(19.7)$ & $10027(22.2)$ & \\
\hline Low level non-manual employee & $4942(10.2)$ & $300(8.6)$ & $4642(10.3)$ & \\
\hline Skilled worker & $10403(21.4)$ & $510(14.6)$ & $9893(21.9)$ & \\
\hline Unskilled worker & $16094(33.1)$ & $1121(32)$ & 14973 (33.2) & \\
\hline Farmer & $5373(11)$ & $399(11.4)$ & $4974(11)$ & \\
\hline Other & $1096(2.3)$ & $485(13.8)$ & $611(1.4)$ & \\
\hline Depression & & & & $<0.01$ \\
\hline No & $47892(98.5)$ & $3421(97.6)$ & 44471 (98.6) & \\
\hline Yes & $732(1.5)$ & $83(2.4)$ & $649(1.4)$ & \\
\hline Anxiety & & & & 0.72 \\
\hline No & $48469(99.7)$ & 3494 (99.7) & 44975 (99.7) & \\
\hline Yes & $155(0.3)$ & $10(0.3)$ & $145(0.3)$ & \\
\hline Cardiorespiratory fitness (stanine scores) & & & & $<0.01$ \\
\hline 1 & $34(0.1)$ & $2(0.1)$ & $32(0.1)$ & \\
\hline 2 & $207(0.4)$ & $15(0.4)$ & $192(0.4)$ & \\
\hline 3 & $2451(5)$ & $207(5.9)$ & $2244(5)$ & \\
\hline 4 & $7020(14.4)$ & $578(16.5)$ & $6442(14.3)$ & \\
\hline 5 & $11447(23.5)$ & $857(24.4)$ & $10590(23.5)$ & \\
\hline 6 & $9215(19)$ & $658(18.8)$ & 8557 (19) & \\
\hline 7 & $5713(11.8)$ & $401(11.4)$ & $5312(11.8)$ & \\
\hline 8 & $4608(9.5)$ & $305(8.7)$ & $4303(9.5)$ & \\
\hline 9 & 7867 (16.2) & $480(13.7)$ & $7387(16.4)$ & \\
\hline Missing & $62(0.1)$ & $1(0.1)$ & $61(0.1)$ & \\
\hline Number of personal friends & & & & 0.72 \\
\hline 0 & $389(0.8)$ & $29(0.8)$ & $360(0.8)$ & \\
\hline $1-3$ & $3260(6.7)$ & $240(6.8)$ & $3020(6.7)$ & \\
\hline $3-5$ & $15195(31.3)$ & $1114(31.8)$ & $14081(31.2)$ & \\
\hline$>5$ & $29006(59.6)$ & $2048(58.4)$ & $26958(59.7)$ & \\
\hline Missing & $774(1.6)$ & $73(2.1)$ & $701(1.6)$ & \\
\hline Confidential discussions with friends & & & & $<0.01$ \\
\hline Never & $2011(4.2)$ & $178(5.1)$ & $1833(4.1)$ & \\
\hline Sometime & 28655 (58.9) & $2061(58.8)$ & $26594(58.9)$ & \\
\hline Quite often & $17072(35.1)$ & $1186(33.8)$ & $15886(35.2)$ & \\
\hline Missing & $886(1.8)$ & $79(2.3)$ & $807(1.8)$ & \\
\hline Has a confidant & & & & $<0.01$ \\
\hline No & 7865 (16.2) & $633(18.1)$ & $7232(16)$ & \\
\hline Yes & 39741 (81.7) & $2772(79.1)$ & 36969 (81.9) & \\
\hline Missing & $1018(2.1)$ & $99(2.8)$ & $919(2)$ & \\
\hline \multicolumn{5}{|l|}{ Number of cigarettes smoked per day } \\
\hline 0 & $19903(40.9)$ & $1216(34.7)$ & $18687(41.4)$ & $<0.01$ \\
\hline $1-10$ & 15310 (31.5) & $1150(32.8)$ & $14160(31.4)$ & \\
\hline
\end{tabular}


Table 1 Continued

\begin{tabular}{|c|c|c|c|c|}
\hline \multirow[b]{2}{*}{ Variables } & \multirow[b]{2}{*}{ Total, n (\%) } & \multicolumn{2}{|c|}{ Death of a parent } & \multirow[b]{2}{*}{$P_{\text {value* }}$} \\
\hline & & $\begin{array}{l}\text { Yes } \\
(n=3504)\end{array}$ & $\begin{array}{l}\text { No } \\
(n=45120)\end{array}$ & \\
\hline$>10$ & $12731(26.2)$ & $1067(30.5)$ & 11664 (25.9) & \\
\hline Missing & $680(1.4)$ & $71(2)$ & $609(1.3)$ & \\
\hline Risky drinking behaviour & & & & $<0.01$ \\
\hline No & $42323(87)$ & $2923(83.4)$ & 39400 (87.3) & \\
\hline Yes & $6267(12.9)$ & $579(16.5)$ & $5688(12.6)$ & \\
\hline Missing & $34(0.1)$ & $2(0.1)$ & $32(0.1)$ & \\
\hline Father's drinking habits & & & & $<0.01$ \\
\hline Never, occasionally or sometimes & 45580 (93.8) & $3048(87)$ & 42532 (94.3) & \\
\hline Often & $1954(4)$ & $175(5)$ & $1779(3.9)$ & \\
\hline Missing & $1090(2.2)$ & $281(8)$ & $809(1.8)$ & \\
\hline Cumulative adverse childhood experiences & & & & $<0.01$ \\
\hline 0 & $9617(19.8)$ & $482(13.8)$ & $9135(20.2)$ & \\
\hline 1 & $18477(38)$ & $1043(29.8)$ & $17434(38.6)$ & \\
\hline 2 & $12173(25)$ & $1061(30.3)$ & $11112(24.6)$ & \\
\hline$\geq 3$ & 8357 (17.2) & $918(26.2)$ & 7439 (16.5) & \\
\hline \multicolumn{5}{|l|}{ Continuous variable, median } \\
\hline Body mass index, $\mathrm{kg} / \mathrm{m}^{2}$ & 20.6 & 20.6 & 20.7 & 0.71 \\
\hline
\end{tabular}

*Men with no missing data on the corresponding variables were included in these analyses.

workers versus (3) farmer or other) and by our cumulative index of adverse childhood experiences $(0,1,2$ or $\geq 3)$ by stratified analyses and formal tests of interaction. In further sensitivity analyses we run logistic regression models to investigate the association between death of a parent (any loss and exposure classified by the parent's cause of death, the deceased parent's gender and the child's age at loss) and hypertension. We deleted listwise in case of missing information on covariates.

We used SAS 9.4 for Windows for the analyses.

\section{Patient and public involvement}

Patients and/or the public were not involved in the design, conduct, reporting or dissemination plans of this research.

\section{RESULTS}

Of the 48624 men included in our study, 3504 (7.21\%) experienced death of a parent before the age of 18 . Characteristics of exposed and unexposed participants are shown in table 1 . The association between covariates and the risk of our outcomes is presented in online supplemental table 1 .

The least square means of SBP and DBP were generally similar between the exposed and the unexposed groups, both when investigating any loss of a parent and when the exposure was classified according to the deceased parent's cause of death and gender, or the child's age at loss (table 2). Men whose mother died due to unnatural causes had a slightly lower DBP than the unexposed in the unadjusted and the SES-adjusted, but not in the fully adjusted models (table 3 ). The results did not change after excluding conscripts whose parent's death was defined through questionnaire-based information (online supplemental table 2). We found no strong evidence that parental SES or cumulative childhood adversity modified the association between parental death and BP (online supplemental table 3). Adjusting for father's drinking behaviour in addition to factors in model 3 did not substantially change the association between death of a father and SBP or DBP (data not shown).

Death of a parent tended to be associated with a slightly increased odds of hypertension; the corresponding multivariate OR (95\% CI) was 1.10 (1 to 1.20). Losing a parent due to natural causes other than CVD was associated with hypertension. Losing a parent due to CVD also tended to be associated with hypertension. There was no association between parental death due to unnatural causes and the risk of hypertension. The point estimates corresponding to the association between death of a parent and hypertension did not differ substantially according to the parent's gender. Risks were slightly higher in case the child was 6-12 or 13-18 years at loss compared with when the loss occurred at earlier ages; these associations were confined only to losses due to natural causes (table 4). 
Table 2 Least square means and 95\% Cls for blood pressure according to exposure to death of a parent during childhood $(\mathrm{N}=48$ 624)

\begin{tabular}{|c|c|c|c|c|c|c|}
\hline \multirow[b]{2}{*}{ Type of exposure } & \multicolumn{2}{|l|}{ Model 1* } & \multicolumn{2}{|l|}{ Model $2 \dagger$} & \multicolumn{2}{|l|}{ Model 3‡ } \\
\hline & LS mean $(95 \% \mathrm{Cl})$ & $P$ value & LS mean $(95 \% \mathrm{Cl})$ & $P$ value & LS mean $(95 \% \mathrm{Cl})$ & $P$ value \\
\hline \multicolumn{7}{|c|}{ Systolic blood pressure, $\mathrm{mm} \mathrm{Hg}$} \\
\hline Any loss & 126.34 (125.95 to 126.72$)$ & 0.24 & 126.35 (125.96 to 126.74$)$ & 0.30 & 128.25 (127.04 to 129.46$)$ & 0.26 \\
\hline \multicolumn{7}{|c|}{ Cause of death of the parent§ } \\
\hline Other natural cause & 126.62 (126.05 to 127.19$)$ & 0.08 & 126.59 (126.02 to 127.16$)$ & 0.12 & 128.31 (127.02 to 129.59$)$ & 0.10 \\
\hline \multicolumn{7}{|c|}{ Gender of deceased parent§ } \\
\hline Mother & 126.36 (125.59 to 127.14$)$ & 0.50 & 126.26 (125.47 to 127.04$)$ & 0.74 & 128.14 (126.74 to 129.53$)$ & 0.51 \\
\hline $13-18$ years & 126.67 (126.06 to 127.28$)$ & 0.07 & 126.69 (126.08 to 127.31$)$ & 0.08 & 128.64 (127.34 to 129.94$)$ & 0.05 \\
\hline \multicolumn{7}{|c|}{ Diastolic blood pressure, $\mathrm{mm} \mathrm{Hg}$} \\
\hline Unexposed & 72.90 (72.82 to 72.99$)$ & - & 72.94 (72.81 to 73.07$)$ & - & 73.99 (73.06 to 74.93$)$ & - \\
\hline Any loss & 72.88 (72.57 to 73.19$)$ & 0.87 & 72.86 (72.55 to 73.17$)$ & 0.63 & 73.86 (72.89 to 74.84$)$ & 0.45 \\
\hline \multicolumn{7}{|c|}{ Cause of death of the parent§ } \\
\hline Unnatural death & 72.16 (71.43 to 72.88$)$ & 0.05 & 72.10 (71.37 to 72.82$)$ & 0.02 & 73.20 (72.02 to 74.39$)$ & 0.06 \\
\hline $\begin{array}{l}\text { Cardiovascular } \\
\text { death }\end{array}$ & 73.42 (72.68 to 74.16$)$ & 0.18 & 73.40 (72.66 to 74.14$)$ & 0.24 & 74.14 (72.94 to 75.33$)$ & 0.60 \\
\hline Other natural cause & 73.13 (72.67 to 73.58$)$ & 0.34 & 73.12 (72.67 to 73.58$)$ & 0.46 & 74.14 (73.10 to 75.18$)$ & 0.40 \\
\hline \multicolumn{7}{|c|}{ Gender of deceased parent§ } \\
\hline 13-18 years & 72.97 (72.49 to 73.45$)$ & 0.80 & 72.99 (72.50 to 73.49$)$ & 0.84 & 74.09 (73.04 to 75.14$)$ & 0.74 \\
\hline
\end{tabular}

*Model 1 was unadjusted.

†Model 2 was adjusted for parental socioeconomic status.

$\ddagger$ Model 3 was adjusted for parental socioeconomic status, depression, anxiety, body mass index, cardiorespiratory fitness, number of friends,

frequency of talking with friends confidentially, having a confidant, number of cigarettes smoked per day and risky drinking behaviour.

§Only men with no missing data on this type of exposure were included.

LS, least square.

\section{DISCUSSION}

We found no strong evidence for an association between the death of a parent during childhood and SBP or DBP in early adulthood. The associations did not differ by the parent's cause of death, the gender of the deceased parent or the child's age at loss. Losing a parent was associated with a slightly increased risk of hypertension; the association was present only in case of losses due to natural causes.

Earlier studies investigating the association between parental death during childhood and elevated BP or hypertension have yielded mixed results. Two studies observed higher SBP and DBP among participants exposed to parental death during childhood than among their unexposed counterparts. ${ }^{720}$ Two other studies found no relation between parental death and BP or hypertension, ${ }^{421}$ whereas one study observed that students who experienced parental death had lower 24-hour ambulatory BP than non-bereaved students. ${ }^{19}$ The reasons for these inconsistent findings are not clear but could be due to differences in study design, sample size, historical birth cohort, the age and the method of BP assessment and considerations about confounding by design or in multivariate models. Findings concerning the association 
Table 3 Least square means and 95\% Cls for systolic blood pressure and diastolic blood pressure, by gender of the deceased parent during childhood and further classified according to the cause of death and the age at loss $(\mathrm{N}=48624)$

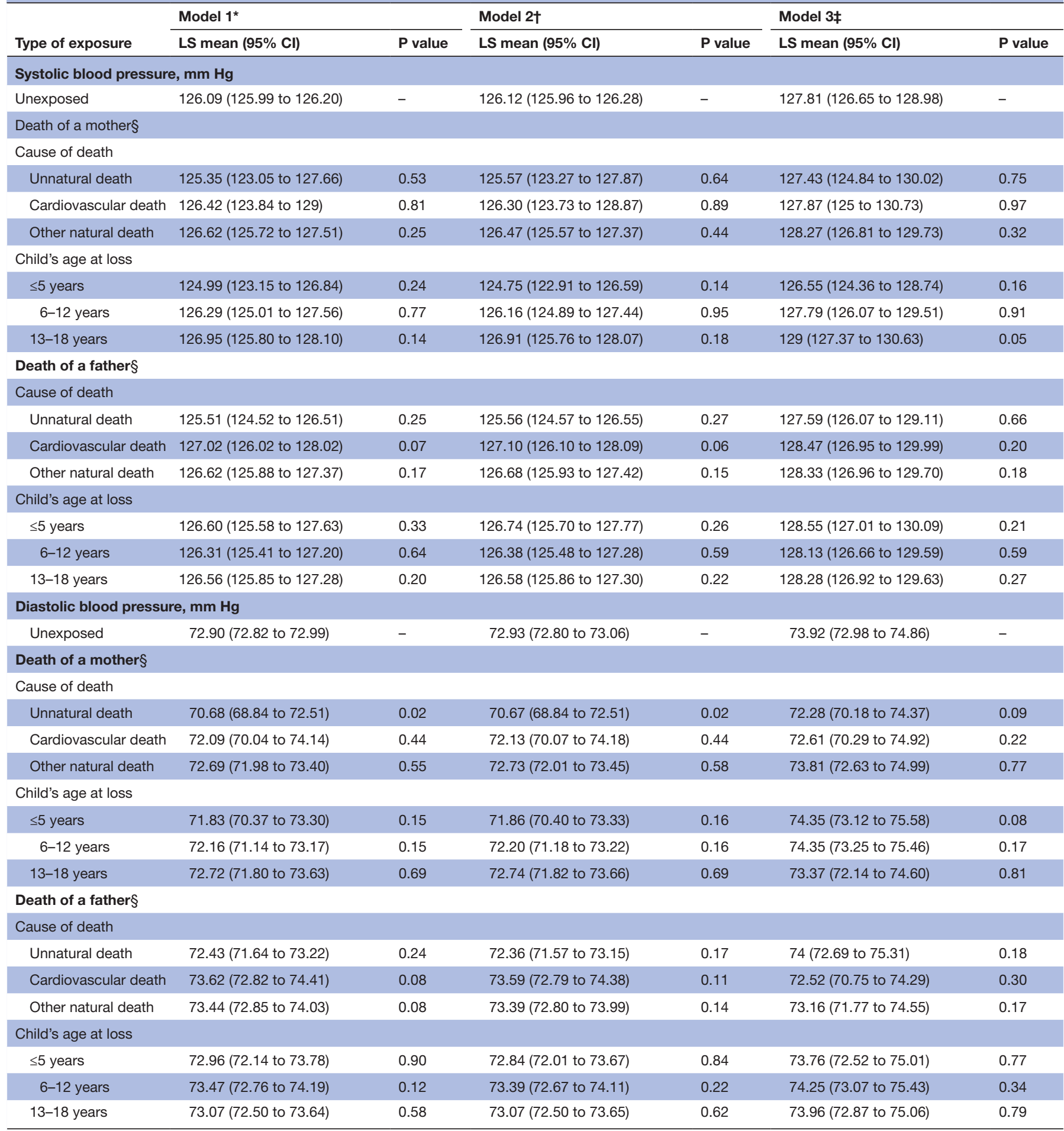

*Model 1 was unadjusted.

†Model 2 was adjusted for parental socioeconomic status.

¥Model 3 was adjusted for parental socioeconomic status, depression, anxiety, body mass index, cardiorespiratory fitness, number of friends, frequency of talking with friends confidentially, having a confidant, number of cigarettes smoked per day and risky drinking behaviour.

$\S$ Only men without missing data on type of exposure were include.

LS, least square.

between other types of childhood adversities-often defined as a cumulative index of events related to abuse, neglect or family dysfunction-and hypertension in middle age or old age are more consistent, ${ }^{153839}$ possibly due to the inclusion of a larger number of adverse life events and biases associated with the retrospective assessment of exposure. Our study extends knowledge in this field by focusing on BP assessed at a young age, using 
Table 4 ORs for high blood pressure at conscription according to exposure to death of a parent during childhood ( $N=48624)$

\begin{tabular}{|c|c|c|c|c|}
\hline & & Model 1* & Model $2 \dagger$ & Model 3‡ \\
\hline Type of exposure & Events/N & OR $(95 \% \mathrm{Cl})$ & OR $(95 \% \mathrm{Cl})$ & OR $(95 \% \mathrm{Cl})$ \\
\hline Unexposed & $9166 / 45120$ & 1 & 1 & 1 \\
\hline \multicolumn{5}{|c|}{ Cause of death of the parent§ } \\
\hline Unnatural death & $119 / 634$ & 0.91 (0.74 to 1.11$)$ & 0.91 (0.74 to 1.11$)$ & $0.93(0.75$ to 1.15$)$ \\
\hline \multicolumn{5}{|l|}{ Child's age at loss } \\
\hline$\leq 5$ years & $218 / 1101$ & 0.97 (0.83 to 1.13$)$ & 0.96 (0.82 to 1.12$)$ & $0.94(0.81$ to 1.11$)$ \\
\hline $6-12$ years & $226 / 979$ & 1.18 (1.01 to 1.37$)$ & 1.16 (1 to 1.36$)$ & 1.15 (0.98 to 1.35$)$ \\
\hline $13-18$ years & $332 / 1424$ & 1.19 (1.05 to 1.35$)$ & 1.19 (1.05 to 1.35$)$ & 1.18 (1.03 to 1.34$)$ \\
\hline \multicolumn{5}{|c|}{ Gender of deceased parent§ } \\
\hline Cardiovascular death & $14 / 79$ & 0.84 (0.47 to 1.51$)$ & 0.83 (0.46 to 1.48$)$ & 0.88 (0.49 to 1.60$)$ \\
\hline Other natural death & $155 / 660$ & $1.20(1$ to 1.44$)$ & 1.18 (0.98 to 1.41$)$ & 1.18 (0.98 to 1.42$)$ \\
\hline \multicolumn{5}{|c|}{ Child's age at mother's death } \\
\hline$\leq 5$ years & $25 / 155$ & 0.75 (0.49 to 1.16$)$ & 0.73 (0.47 to 1.12$)$ & 0.65 (0.41 to 1.04$)$ \\
\hline $6-12$ years & $81 / 323$ & 1.31 (1.02 to 1.69$)$ & 1.29 (1 to 1.66$)$ & 1.27 (0.97 to 1.65$)$ \\
\hline $13-18$ years & $90 / 398$ & 1.15 (0.91 to 1.45$)$ & 1.14 (0.90 to 1.44$)$ & 1.19 (0.93 to 1.52$)$ \\
\hline Father & $493 / 2180$ & 1.15 (1.03 to 1.27$)$ & 1.15 (1.03 to 1.28$)$ & 1.13 (1.01 to 1.26$)$ \\
\hline \multicolumn{5}{|l|}{ Cause of father's death } \\
\hline Unnatural death & $98 / 535$ & 0.88 (0.71 to 1.10$)$ & 0.88 (0.70 to 1.10$)$ & 0.91 (0.72 to 1.14$)$ \\
\hline \multicolumn{5}{|l|}{$\leq 5$ years } \\
\hline \multicolumn{5}{|l|}{ Cause of parent's death } \\
\hline Unnatural death & $17 / 126$ & 0.61 (0.37 to 1.02$)$ & 0.61 (0.36 to 1.02$)$ & 0.61 (0.36 to 1.05$)$ \\
\hline Cardiovascular death & $12 / 61$ & $0.96(0.51$ to 1.81$)$ & 0.97 (0.52 to 1.84$)$ & 1.01 (0.53 to 1.93$)$ \\
\hline Other natural death & $57 / 258$ & 1.11 (0.83 to 1.49$)$ & 1.09 (0.81 to 1.47$)$ & $1.04(0.76$ to 1.41$)$ \\
\hline \multicolumn{5}{|l|}{$6-12$ years } \\
\hline \multicolumn{5}{|l|}{ Cause of parent's death } \\
\hline Unnatural death & $41 / 229$ & 0.86 (0.61 to 1.20$)$ & 0.84 (0.60 to 1.19$)$ & 0.85 (0.59 to 1.21$)$ \\
\hline Cardiovascular death & $46 / 185$ & 1.30 (0.93 to 1.81$)$ & 1.29 (0.92 to 1.81$)$ & 1.24 (0.88 to 1.77$)$ \\
\hline Other natural death & $139 / 565$ & 1.28 (1.06 to 1.55$)$ & 1.26 (1.04 to 1.53$)$ & 1.24 (1.01 to 1.52$)$ \\
\hline \multicolumn{5}{|l|}{$13-18$ years } \\
\hline \multicolumn{5}{|l|}{ Cause of parent's death } \\
\hline Unnatural death & $61 / 279$ & $1.10(0.83$ to 1.46$)$ & 1.11 (0.84 to 1.48$)$ & 1.15 (0.86 to 1.54$)$ \\
\hline Cardiovascular death & $84 / 360$ & 1.19 (0.93 to 1.53$)$ & 1.19 (0.93 to 1.52$)$ & 1.12 (0.87 to 1.45$)$ \\
\hline Other natural death & $187 / 785$ & 1.23 (1.04 to 1.45$)$ & $1.22(1.03$ to 1.44$)$ & 1.21 (1.02 to 1.44$)$ \\
\hline
\end{tabular}

${ }^{*}$ Model 1 was unadjusted.

†Model 2 was adjusted for parental socioeconomic status.

†Model 3 was adjusted for parental socioeconomic status, depression, anxiety, body mass index, cardiorespiratory fitness, number of friends, frequency of talking with friends confidentially, having a confidant, number of cigarettes smoked per day and risky drinking behaviour.

§Only men with no missing data on this type of exposure were included. 
prospectively recorded information on parent's death from a high-quality nationwide register, rather than relying on retrospectively collected, questionnaire-based information on exposure and analysing a very large sample that allowed us to conduct subanalyses to test hypotheses that may be supportive of a causal effect, if any.

Since an important challenge in studies regarding the association between bereavement and CVDs is related to the separation of the stress-related effect from confounding by genetic and environmental cardiovascular risk factors shared by family members, we performed analyses by the parents' cause of death classified as cardiovascular, other natural and unnatural deaths. Furthermore, to explore dose-response patterns and potential sensitive periods, we performed analyses according to the type of deceased parent or age at loss. We found no association between parental death during childhood and our continuous BP measures neither in case of overall exposure, nor when exposure was categorised by the parents' cause of death or gender or the child's age at loss. These results are indicative of a lack of a causal effect.

The finding that a modestly increased hypertension risk was observed only in case of parental deaths due to natural causes but not in case of parental deaths due to unnatural causes-which are often associated with more severe stress ${ }^{616} 23$ - suggests that residual confounding by familial cardiovascular risk factors is a likely explanation for the association between parental death during childhood and hypertension. A family history of metabolic disorders and early CVD is a well-established risk factor of hypertension in children and youth. ${ }^{56}$ An alternative explanation may be that severe stress increases the risk of hypertension in youth only among individuals with a genetic susceptibility to cardiometabolic disorders; children exposed to parental death due to natural causes are more likely to have such a susceptibility than children who lost a parent due to unnatural causes. A further though-in light of the fact that exposure in young age was not associated with the outcome-less likely explanation for the association between parental death due to natural causes and hypertension is that natural deaths may be proceeded by a long period of disease which may induce chronic stress for family members. ${ }^{57}$ The stronger association between parental death in adolescence and hypertension than in earlier periods of life-besides better statistical power-is also likely to be due to residual confounding, given the higher proportion of parental deaths related to cardiometabolic conditions in the older age group.

A possible explanation for the limited evidence for an association between the death of a parent and BP in our study, in contrast to the large body of evidence documenting a link between psychological stress and hypertension in adulthood ${ }^{58}$ and childhood adversities and hypertension in middle age or old age ${ }^{153839}$ may be related to the age of the BP assessment. Though children who lost a parent may experience chronic stress, the accumulation of further childhood (eg, adverse socioeconomic circumstances, low social support, abuse or neglect, poor mental health) or adult adversities (eg, low educational attainment, difficulties in attaching to a partner, difficulties on the labour marker) and the subsequent allostatic load may need to act for a longer period than what we studied to induce abnormal BP changes. ${ }^{59}$ At the age of $18-20$ years differences in BP may still be small across individuals. ${ }^{43}$ Allostatic load may need to interact with the age-related vulnerability to increase BP later in life. This hypotheses is supported by findings of Su and associates who assessed $\mathrm{BP}$ on average 13 times between the age of 5 and 38 years, and found that mean SBP and DBP were similar in the first two decades of life among groups exposed and unexposed to adverse childhood experiences, but from the third decade of life differences among exposure groups in levels of BP became evident and with time increasingly important; the increase in mean BP was steeper with a higher number of adverse childhood experiences. ${ }^{43}$

Our findings need to be considered also in light of our study's limitations. First, since only one or two BP measurements were taken at conscription, we did not have the possibility to consider intra-individual variations in $\mathrm{BP}^{60}$ neither to reduce an eventual bias related to white-coat hypertension. Nevertheless, several measurements or ambulatory BP monitoring ${ }^{1961}$ may not be feasible in large epidemiological studies such as ours, as these measures may limit the sample size and may generate selection bias, for example, children with parental death and/or hypertension may be more or less likely to participate in such a study compared with others. The potential misclassification introduced by the single measurement in our study is likely to be non-differential and may eventually result in an underestimation of the true effect. Nevertheless, the BP measurement at conscription followed the standard measurement for screening for hypertension in primary care. Though one measurement of BP is not sufficient to confirm a clinical diagnosis of hypertension, ${ }^{62}$ it has a screening value as the $\mathrm{BP}$ measure in this cohort has been reported to be an important predictor of later CVD and mortality. ${ }^{46} 63$ Future studies with repeated measurements of BP ranging from childhood to later adulthood are needed to investigate the link between parental death and BP. Second, since the conscription cohort included only men, it is not clear whether the results can be generalised to women. Though women may be more sensitive to psychological stress with respect to hypertension than men, ${ }^{64}$ earlier studies in this field investigating the association between adverse childhood experiences and youth BP have mixed results in term of gender differences. ${ }^{4365} 66$ Similarly, it is not clear to what extent our findings may be generalisable to current Swedish young adults or to populations with different risk factor profiles, support for bereaved children and healthcare ${ }^{67}$ Third, since information on most of our covariates was available only from conscription, we do not know whether they are confounders or mediators of the investigated associations. Though theoretical considerations and our 
measurement post-exposure favour regarding them as mediators, we cannot exclude the possibility that some of these measures are indicators of familial characteristics and may thus be proxies for confounding by factors that cluster in families. ${ }^{17}$ Nevertheless, adjustment for factors in model 3 did not substantially affect our estimates; these covariates were generally weakly associated with hypertension. The finding that natural deaths but not unnatural deaths, which are less likely to be affected by familial cardiovascular risk, were associated with an increased hypertension risk and that associations were unchanged after adjusting for these suggests the presence of confounding by factors that we did not consider; potential candidates include genetics, further socioeconomic factors, housing, diet and familial cardiometabolic disorders. Fourth, though our sample was very large, the power in some of our subanalyses, for example, when categorising exposure according to the deceased parents' gender, cause of death and the child's age at loss and the risk of hypertension, may have been low to detect a modest effect at the conventional $\mathrm{p}<0.05$ level.

We found no evidence that death of a parent was associated with continuous SBP and DBP measured at the age of 18-20. The fact that the association between loss of a parent and the modest risk of hypertension was observed in case of parental deaths due to natural causes but not in case of unnatural deaths, may be indicative of residual confounding by genetic and environmental factors shared by family members.

\section{Author affiliations}

${ }^{1}$ Department of Global Public Health, Karolinska Institutet, Stockholm, Sweden ${ }^{2}$ Department of Public Health Sciences, Stockholm University, Stockholm, Sweden ${ }^{3}$ Institute of Environmental Medicine, Karolinska Institutet, Stockholm, Sweden ${ }^{4}$ Department of Public Health and General Practice, Faculty of Medicine, Norwegian University of Science and Technology, Trondheim, Norway

${ }^{5}$ Centre for Health Equity Studies, Stockholm University and Karolinska Institutet, Stockholm, Sweden

${ }^{6}$ Centre for Epidemiology and Community Medicine, Stockholm County Council, Stockholm, Sweden

${ }^{7}$ Statistical Office, Capital Institute of Pediatrics, Beijing, China

Contributors Conceptualisation: HC, KDL and IJ. Data curation: HC, TH and KDL. Formal analysis: HC. Funding acquisition: KDL and HC. Methodology: HC, KDL, TH IJ, MR, YF, LM and YL. Resources: TH and KDL. Supervision: KDL, TH, MR, and YF. Writing — original draft: HC. Writing—review and editing: HC, KDL, TH, IJ, MR, YF, YL and LM.

Funding The study was supported by the Swedish Council for Working Life and Social Research (grant number: 2015-00837), by Karolinska Institutet's Research Foundation (grant number: 2018-01924) and by the China Scholarship Council (grant number: 201700260296).

Competing interests None declared.

Patient consent for publication Not required.

Ethics approval The study was approved by the Regional Ethics Board in Stockholm (reference numbers: 2004-693/5, 2008/323-32 and 2010/604-32).

Provenance and peer review Not commissioned; externally peer reviewed.

Data availability statement Data may be obtained from a third party and are not publicly available.

Supplemental material This content has been supplied by the author(s). It has not been vetted by BMJ Publishing Group Limited (BMJ) and may not have been peer-reviewed. Any opinions or recommendations discussed are solely those of the author(s) and are not endorsed by BMJ. BMJ disclaims all liability and responsibility arising from any reliance placed on the content. Where the content includes any translated material, BMJ does not warrant the accuracy and reliability of the translations (including but not limited to local regulations, clinical guidelines, terminology, drug names and drug dosages), and is not responsible for any error and/or omissions arising from translation and adaptation or otherwise.

Open access This is an open access article distributed in accordance with the Creative Commons Attribution 4.0 Unported (CC BY 4.0) license, which permits others to copy, redistribute, remix, transform and build upon this work for any purpose, provided the original work is properly cited, a link to the licence is given, and indication of whether changes were made. See: https://creativecommons.org/ licenses/by/4.0/.

\section{ORCID IDs}

Hua Chen http://orcid.org/0000-0002-4884-3360

Krisztina D. László http://orcid.org/0000-0002-4695-477X

\section{REFERENCES}

1 Breslau N, Wilcox HC, Storr CL, et al. Trauma exposure and posttraumatic stress disorder: a study of youths in urban America. $J$ Urban Health 2004;81:530-44.

2 Li J, Vestergaard M, Cnattingius S, et al. Mortality after parental death in childhood: a nationwide cohort study from three Nordic countries. PLoS Med 2014;11:e1001679.

3 Hjern A, Berg L, Arat A. Children as next of kin in Sweden BSArapport. Kalmar 2017;28.

4 Schooling CM, Jiang C, Lam TH, et al. Parental death during childhood and adult cardiovascular risk in a developing country: the Guangzhou Biobank cohort study. PLoS One 2011;6:e19675.

5 Sherr L, Croome N, Clucas C, et al. Differential effects of single and double parental death on child emotional functioning and daily life in South Africa. Child Welfare 2014;93:149-72.

6 Dowdney L. Childhood bereavement following parental death. J Child Psychol Psychiatry 2000;41:819-30.

7 Luecken LJ. Childhood attachment and loss experiences affect adult cardiovascular and cortisol function. Psychosom Med 1998:60:765-72.

8 Berg L, Rostila M, Saarela J, et al. Parental death during childhood and subsequent school performance. Pediatrics 2014;133:682-9.

9 Geulayov G, Gunnell D, Holmen TL, et al. The association of parental fatal and non-fatal suicidal behaviour with offspring suicidal behaviour and depression: a systematic review and meta-analysis. Psychol Med 2012;42:1567-80.

10 Berg L, Rostila M, Hjern A. Parental death during childhood and depression in young adults - a national cohort study. J Child Psycho Psychiatry 2016;57:1092-8.

11 Hamdan S, Mazariegos D, Melhem NM, et al. Effect of parental bereavement on health risk behaviors in youth: a 3-year follow-up. Arch Pediatr Adolesc Med 2012;166:216-23.

12 Hamdan S, Melhem NM, Porta G, et al. Alcohol and substance abuse in parentally bereaved youth. J Clin Psychiatry 2013;74:828-33.

13 Oliveira AJ, Rostila M, Saarela J, et al. The influence of bereavement on body mass index: results from a national Swedish survey. PLoS One 2014;9:e95201.

14 Alciati A, Gesuele F, Casazza G, et al. The relationship between childhood parental loss and metabolic syndrome in obese subjects. Stress Health 2013;29:5-13.

15 Obi IE, McPherson KC, Pollock JS. Childhood adversity and mechanistic links to hypertension risk in adulthood. Br J Pharmacol 2019;176:1932-50.

16 Stroebe M, Schut $\mathrm{H}$, Stroebe W. Health outcomes of bereavement. Lancet 2007;370:1960-73.

17 Chen $\mathrm{H}$, Hemmingsson T, Forsell $\mathrm{Y}$, et al. Death of a parent during childhood and the risk of ischemic heart disease and stroke in adult men. Psychosom Med 2020;82:810-6.

18 Smith KR, Hanson HA, Norton MC, et al. Survival of offspring who experience early parental death: early life conditions and later-life mortality. Soc Sci Med 2014;119:180-90.

19 Luecken LJ, Kraft A, Appelhans BM, et al. Emotional and cardiovascular sensitization to daily stress following childhood parental loss. Dev Psychol 2009;45:296-302.

20 Anderson EL, Caleyachetty R, Stafford M, et al. Prospective associations of psychosocial adversity in childhood with risk factors for cardiovascular disease in adulthood: the MRC national survey of health and development. Int J Equity Health 2017;16:170. 
21 Stein DJ, Scott K, Haro Abad JM, et al. Early childhood adversity and later hypertension: data from the world mental health survey. Ann Clin Psychiatry 2010;22:19-28.

22 Rostila M, Berg L, Saarela J, et al. Experience of sibling death in childhood and risk of death in adulthood: a national cohort study from Sweden. Am J Epidemiol 2017;185:1247-54.

23 Brunner E. Stress mechanisms in coronary heart disease, 2002.

24 Fuchs A, Möhler E, Reck C, et al. The early mother-to-child bond and its unique prospective contribution to child behavior evaluated by mothers and teachers. Psychopathology 2016;49:211-6.

25 Kirwin KM, Hamrin V. Decreasing the risk of complicated bereavement and future psychiatric disorders in children. $J$ Child Adolesc Psychiatr Nurs 2005;18:62-78.

26 Koehn AJ, Kerns KA. Parent-child attachment: meta-analysis of associations with parenting behaviors in middle childhood and adolescence. Attach Hum Dev 2018;20:378-405.

27 Pabayo R, Molnar BE, Kawachi I. Witnessing a violent death and smoking, alcohol consumption, and marijuana use among adolescents. J Urban Health 2014;91:335-54.

28 Chen X, Wang Y. Tracking of blood pressure from childhood to adulthood: a systematic review and meta-regression analysis. Circulation 2008;117:3171-80.

29 Merai R, Siegel C, Rakotz M, et al. CDC grand rounds: a public health approach to detect and control hypertension. MMWR Morb Mortal Wkly Rep 2016;65:1261-4.

30 Falkner B, DeLoach S, Keith SW, et al. High risk blood pressure and obesity increase the risk for left ventricular hypertrophy in AfricanAmerican adolescents. J Pediatr 2013;162:94-100.

31 Sun SS, Grave GD, Siervogel RM, et al. Systolic blood pressure in childhood predicts hypertension and metabolic syndrome later in life. Pediatrics 2007:119:237-46.

32 Rovio SP, Pahkala K, Nevalainen J, et al. Cardiovascular Risk Factors From Childhood and Midlife Cognitive Performance: The Young Finns Study. J Am Coll Cardiol 2017;69:2279-89.

33 Sundin P-O, Udumyan R, Sjöström P, et al. Predictors in adolescence of ESRD in middle-aged men. Am J Kidney Dis 2014;64:723-9.

34 Franklin BA, Chaddha A. Resting heart rate and blood pressure as indices of cardiovascular and mortality risk: is lower invariably better? J Cardiopulm Rehabil Prev 2018;38:353-7.

35 Lim SS, Vos T, Flaxman AD, et al. A comparative risk assessment of burden of disease and injury attributable to 67 risk factors and risk factor clusters in 21 regions, 1990-2010: a systematic analysis for the global burden of disease study 2010. Lancet 2012;380:2224-60.

36 Kit BK, Kuklina E, Carroll MD, et al. Prevalence of and trends in dyslipidemia and blood pressure among US children and adolescents, 1999-2012. JAMA Pediatr 2015;169:272-9.

37 Noubiap JJ, Essouma M, Bigna JJ, et al. Prevalence of elevated blood pressure in children and adolescents in Africa: a systematic review and meta-analysis. Lancet Public Health 2017;2:e375-86.

38 Springer KW, Sheridan J, Kuo D, et al. Long-term physical and mental health consequences of childhood physical abuse: results from a large population-based sample of men and women. Child Abuse Negl 2007;31:517-30.

39 Parrish C, Surkan PJ, Martins SS, et al. Childhood adversity and adult onset of hypertension and heart disease in São Paulo, Brazil. Prev Chronic Dis 2013;10:E205.

40 Gooding HC, Milliren CE, Austin SB, et al. Child abuse, resting blood pressure, and blood pressure reactivity to psychosocial stress. $J$ Pediatr Psychol 2016;41:5-14

41 Doom JR, Mason SM, Suglia SF, et al. Pathways between childhood/ adolescent adversity, adolescent socioeconomic status, and longterm cardiovascular disease risk in young adulthood. Soc Sci Med 2017;188:166-75.

42 Su S, Wang X, Kapuku GK, et al. Adverse childhood experiences are associated with detrimental hemodynamics and elevated circulating endothelin-1 in adolescents and young adults. Hypertension 2014;64:201-7.

43 Su S, Wang X, Pollock JS, et al. Adverse childhood experiences and blood pressure trajectories from childhood to young adulthood: the Georgia stress and heart study. Circulation 2015;131:1674-81.

44 Falkstedt D, Hemmingsson T, Rasmussen F, et al. Body mass index in late adolescence and its association with coronary heart disease and stroke in middle age among Swedish men. Int $J$ Obes 2007;31:777-83.

45 Lindgren M, Robertson J, Adiels M, et al. Resting heart rate in late adolescence and long term risk of cardiovascular disease in Swedish men. Int J Cardiol 2018;259:109-15.

46 Sundström J, Neovius M, Tynelius P, et al. Association of blood pressure in late adolescence with subsequent mortality: cohort study of Swedish male conscripts. BMJ 2011;342:d643.

47 Britton KA, Gaziano JM, Djoussé L. Normal systolic blood pressure and risk of heart failure in US male physicians. Eur J Heart Fail 2009;11:1129-34.

48 Muntner P, Shimbo D, Carey RM, et al. Measurement of blood pressure in humans: a scientific statement from the American heart association. Hypertension 2019;73:e35-66.

49 Flint AC, Conell C, Ren X, et al. Effect of systolic and diastolic blood pressure on cardiovascular outcomes. N Engl J Med 2019;381:243-51.

50 Carey RM, Aronow WS, Casey DE. ACC/AHA/AAPA/ABC/ACPM/ AGS/APhA/ASH/ASPC/NMA/PCNA guideline for the prevention, detection, evaluation, and management of high blood pressure in adults: a report of the American College of Cardiology/American heart association Task force on clinical practice guidelines 2017.

51 Falkstedt D, Lundberg I, Hemmingsson T. Childhood socio-economic position and risk of coronary heart disease in middle age: a study of 49,321 male conscripts. Eur J Public Health 2011;21:713-8.

52 Larsson D, Hemmingsson T, Allebeck P, et al. Self-rated health and mortality among young men: what is the relation and how may it be explained? Scand J Public Health 2002;30:259-66.

53 Suglia SF, Koenen KC, Boynton-Jarrett R, et al. Childhood and adolescent adversity and cardiometabolic outcomes: a scientific statement from the American heart association. Circulation 2018;137:e15-28.

54 Hughes K, Bellis MA, Hardcastle KA, et al. The effect of multiple adverse childhood experiences on health: a systematic review and meta-analysis. Lancet Public Health 2017;2:e356-66.

55 Felitti VJ. The relation between adverse childhood experiences and adult health: turning gold into lead. Perm J 2002;6:44-7.

56 Kawabe H, Azegami T, Takeda A, et al. Features of and preventive measures against hypertension in the young. Hypertens Res 2019;42:935-48

57 Chen R, Fall K, Czene K, et al. Impact of parental cancer on IQ, stress resilience, and physical fitness in young men. Clin Epidemiol 2018;10:593-604.

58 Liu M-Y, Li N, Li WA, et al. Association between psychosocial stress and hypertension: a systematic review and meta-analysis. Neurol Res 2017;39:573-80. doi:10.1080/01616412.2017.1317904

59 Kuh D, Ben-Shlomo Y. A life course approach to chronic disease epidemiology. 2nd edn. Oxford: Oxford University Press, 2004.

60 Islam MS. Hypertension: from basic research to clinical practice. Adv Exp Med Biol 2017;956:1-2.

61 Buckley T, Mihailidou AS, Bartrop R, et al. Haemodynamic changes during early bereavement: potential contribution to increased cardiovascular risk. Heart Lung Circ 2011;20:91-8.

62 Flynn JT, Kaelber DC, Baker-Smith CM, et al. Clinical practice guideline for screening and management of high blood pressure in children and adolescents. Pediatrics 2017;140 doi:10.1542/ peds.2017-1904

63 Falkstedt D, Koupil I, Hemmingsson T. Blood pressure in late adolescence and early incidence of coronary heart disease and stroke in the Swedish 1969 conscription cohort. $J$ Hypertens 2008;26:1313-20.

64 Di Pilla M, Bruno RM, Taddei S, et al. Gender differences in the relationships between psychosocial factors and hypertension. Maturitas 2016;93:58-64.

65 Dietz LJ, Pham S, Melhem N, et al. Blood pressure recovery to social stress in parentally bereaved and non-bereaved youths. J Psychosom Res 2018;113:58-65.

66 Luecken LJ, Roubinov DS. Hostile behavior links negative childhood family relationships to heart rate reactivity and recovery in young adulthood. Int J Psychophysiol 2012;84:172-9.

67 Rostila M. Commentary: childhood parental loss and adulthood health: discussing the role of parental cause of death, child's age at death and historical context. Soc Sci Med 2015;131:190-2. 